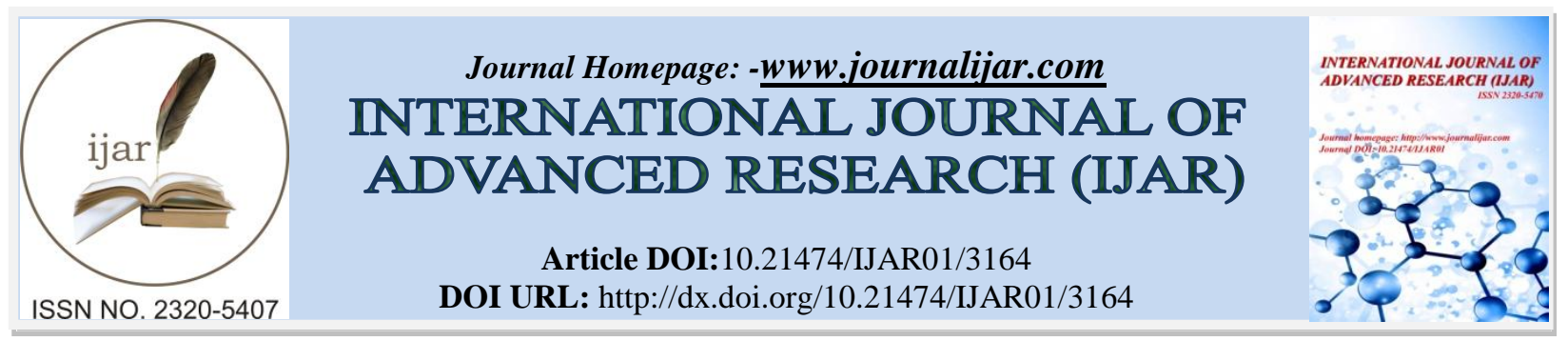

RESEARCH ARTICLE

\title{
SKIN CARE ROUTINE AMONG FEMALE MEDICAL STUDENTS AT KING ABDULAZIZ UNIVERSITY HOSPITAL (KAUH), JEDDAH, SAUDI ARABIA.
}

\section{Wa'ad Alqulaity ${ }^{1}$, Abdullah Sheitt ${ }^{2}$, Duaa Bakheet ${ }^{2}$, Mawaddah Tallab ${ }^{2}$ and Sameer Zimmo ${ }^{3}$.}

1. Medical student, Faculty of medicine, King Abdulaziz University, Saudi Arabia.

2. Medical Intern, Faculty of medicine, King abdulaziz university hospital, Saudi Arabia.

3. Professor \& consultant dermatologist, Department of dermatology, Faculty of medicine, King abdulaziz university hospital, Saudi Arabia.

\section{Manuscript Info}

[.........................

Manuscript History

Received: 15 December 2016

Final Accepted: 07 January 2017

Published: February 2017

\section{Abstract}

Objective:-To Asses Attitudes and behavior of female medical students related to facial skin care routine and to study factors that influence buying-decisions of skin care products.

Study design:-Cross-sectional study.

Setting:-King abdulaziz university hospital.

Subjects and Methods:-Self-administered questionnaire was conducted randomly to 301 female medical students from February 2016 to May 2016.

Descriptive analysis was done for all the data in order to obtain the frequencies and percentages needed.

Results:-Results indicated that majority of students (76.7\%) do not follow regular skin care routine, Further analysis indicated that (66\%)don't use sunblock and (29\%)reported to have previous history of sunburn.

Most commonly used skin products were body lotions and moisturizers (74\%), The use of makeup was obviously higher than the use of skin care facials.

Among the study sample, factors that were distinguished as an evaluative criteria to participants when buying products were greatly affected by brand of product $(68.7 \%)$ followed by friend's recommendations $(51.3 \%)$, one of the factors affects buying behaviour is price of a product, our Students had a little concern regarding price (32\%) in comparison to other factors.

Results also revealed that majority of respondents never cared to check ingredients of their products(48\%).

Conclusion: Our society need to be more educated about the importance of getting a proper skin care routine, further studies with wider distribution of the questioner in different cities and to different age groups is advisable.

\section{Introduction:-}


The skin, is the body's largest organ, it helps to secure the integrity of the host and at the same time, allows the individual to communicate with the outside world. ${ }^{(1)}$

Skin care is an essential part of personal hygiene and well-being. The proper care of skin is important as unclean skin favors the development of pathogenic organisms and infections. ${ }^{(2)}$

Healthy and functioning skin barrier is an important protector against dehydration, penetration of various microorganisms, allergens, irritants, reactive oxygen species and radiation. The skin barrier may be specifically adjusted to allow penetration, for this reason daily skin care may increase skin regeneration, elasticity, smoothness, and thus temporarily change the skin condition. ${ }^{(3)} \mathrm{A}$ study revealed that the focus is found to be more on skincare in East Asia and on make-up in Southeast Asia and India. ${ }^{(4)}$

Sunscreen use is a modifiable behavior that can help reduce the risk for skin cancer, prevent sunburns, mitigate photo-aging, and treat photosensitive dermatomes. ${ }^{(5)}$ Researchers from the Centers for Disease Control and Prevention (CDC) examined the results of a 2013 survey that asked participants how often they use sunscreen when outside in the sun for more than an hour. Only 14.3 percent of men and 29.9 percent of women reported that they regularly use sunscreen on both their face and other exposed skin. ${ }^{(6)}$

Choosing the right ingredient of skin product for each skin type is essential, as various skin care preparations are not tolerated, and they may induce skin irritation. Increasing knowledge and awareness of the benefits and optimal use of skin products can improve outcomes.

In an effort to protect consumers' rights to information and to promote their freedom of choice, the South Korean government has been enforcing a policy called the cosmetics full ingredients list system since 2008, which requires cosmetics manufacturers to list all of the ingredients used in their products ${ }^{(7)}$, this sheds a light on the importance of checking the ingredients before buying products.

Brand satisfaction is perceived as an important issue on skin care industry. Obviously, customers are the important stakeholders in organizations and their satisfaction is a priority to the company. ${ }^{(8)}$ In a study was conductedin 14cities, regarding taking a look at important aspects when buying make-up, results suggested that in Seoul, the criteria for decision-making are different from other cities, with environmental friendliness among the top considerations, alongside good basic quality/functions and brand reputation. In contrast to Hong Kong and Taipei where, in addition to quality/functions, price was an important factor, in all three Chinese cities, reasonable price and brand image rank near the top for both make-up and skincare. ${ }^{(4)}$

To our knowledge, adequate studies regarding the skin care routine and the methods of selecting the correct skin products are still lacking in Saudi Arabia.

Our aim in this study was to explore theskin care routine among female students at king AbdulazizUniversity, and to focus on their considerations whenbuyingskin care products.

\section{Objectives:-}

Primary objective:-

To explore attitudes and behavior of Female medical students related to facial skin care routine.

\section{Secondary objectives:-}

1. Factors that influence buying decisions related to choosing facial skin care products

2. Identify the most commonly used skin products.

\section{Materials and Methods:-}

The study protocol was reviewed and approved by King Abdulaziz University Hospital Health Research and Ethics committee. 
This was a Cross-sectional study .

A self-administered questionnaire was conducted randomly to 301 Female students (aged 18-23 years old) at King Abdulaziz Universityhospital,Jeddah, SaudiArabia, during the period (February 2016 to May 2016). There were no exclusion criteria.

Data was collected using a data collection sheet that includes for example demographic information like name, age and nationality.

Regarding Skin care routine we first determined if students wereroutinely using regular facials and sunscreen,consulting dermatologists before choosing skin products and if there was a previous history of skin irritations to cosmetics.

There wasalso few questionsfocusing on skin type and the most important buying behaviors influencing their decision-making when choosing skin/make-up products such as type of ingredients, brand of product, friend's recommendations, price, packaging and convenience.

\section{Statistical Analysis:-}

In the present study, data was coded and entered into the statistical Package for Social Sciences (SPSS version 20). Descriptive analysis was done for all the data in order to obtain the frequencies and percentages needed.

Descriptive statistics (Frequency tables, Cross tabulation and Charts)

\section{Results:-}

A total of 301 female medical students were included in our study. The background characteristics of the study population are shown in (Table 1.)

Most of ourfemale medical students (76.7\%) do not follow regular skin care routine,Further analysis indicated that (66\%)of students don't use sunblock before sun-exposure and (29\%)reported to have a past history of sunburn.

Most commonly used skin products among our study sample were sequentially: body lotions and moisturizers (74\%), sunscreen $(30 \%)$ and also other products as visualized in "Fig. 1".

Results regarding frequency of using makeup products are shown in (Table 2.)

Reactions to different kinds of cosmetics is increasingly recognized as a relevant problem,a lot of our students reported to have history of reaction to some cosmetics $(38.7 \%)$ and unfortunately most of them $(44.9 \%)$ never consulted dermatologists regardingtheir skin concerns nor for their opinion before choosing skin/make-up products.

As shown in "Fig. 2"Factors that were distinguished as being important evaluative criteria in buying products to our participants were greatly affected mainly by brand of product $(68.7 \%)$ followed by their friend's recommendations $(51.3 \%)$. One of the factors that can have an effect on buying behaviour is the price of a product, studentshad a little concern regarding price of the product (32\%) in comparison to other factors.

In addition to the buying factors related to choosing skin products, ingredients of the product playalso an important role, results revealed that majority of our students never cared to check the ingredient of product before buying it $(48.7 \%)$, and $(33 \%)$ of them preferred to choose the natural ingredients while $(22 \%)$ looked for oil-free ingredients, $(10.3 \%)$ alcohol-free ingredients, (5\%) dye-free, (4.7\%) petroleum-free. "Fig. 3"

Table 1:-Nationality and skin type of participants.

\begin{tabular}{|c|c|}
\hline Questions & Value \\
\hline Nationality & $280(93.00 \%)$ \\
\hline Saudi & $21(7.00 \%)$ \\
\hline Non- Saudi & $154(51.20 \%)$ \\
\hline Skin type & $54(17.90 \%)$ \\
\hline Combination skin. & \\
\hline Oily skin &
\end{tabular}




\begin{tabular}{|c|c|}
\hline Dry skin & $45(15.00 \%)$ \\
\hline I don't know what is my skin type & $24(8.00 \%)$ \\
\hline Normal skin & $24(8.00 \%)$ \\
\hline
\end{tabular}

Table 2:-Frequency of using makeup.

\begin{tabular}{|l|l|l|l|}
\hline \multicolumn{2}{|l|}{ How many times do you wear makeup? } & Frequency & Percent \\
\hline \multirow{4}{*}{ Valid } & Daily & 72 & 24.0 \\
\cline { 2 - 4 } & 3-4 times /week & 64 & 21.3 \\
\cline { 2 - 4 } & Once per week. & 60 & 20.0 \\
\cline { 2 - 4 } & Rarely & 104 & 34.7 \\
\cline { 2 - 4 } & Total & 300 & 100.0 \\
\hline
\end{tabular}

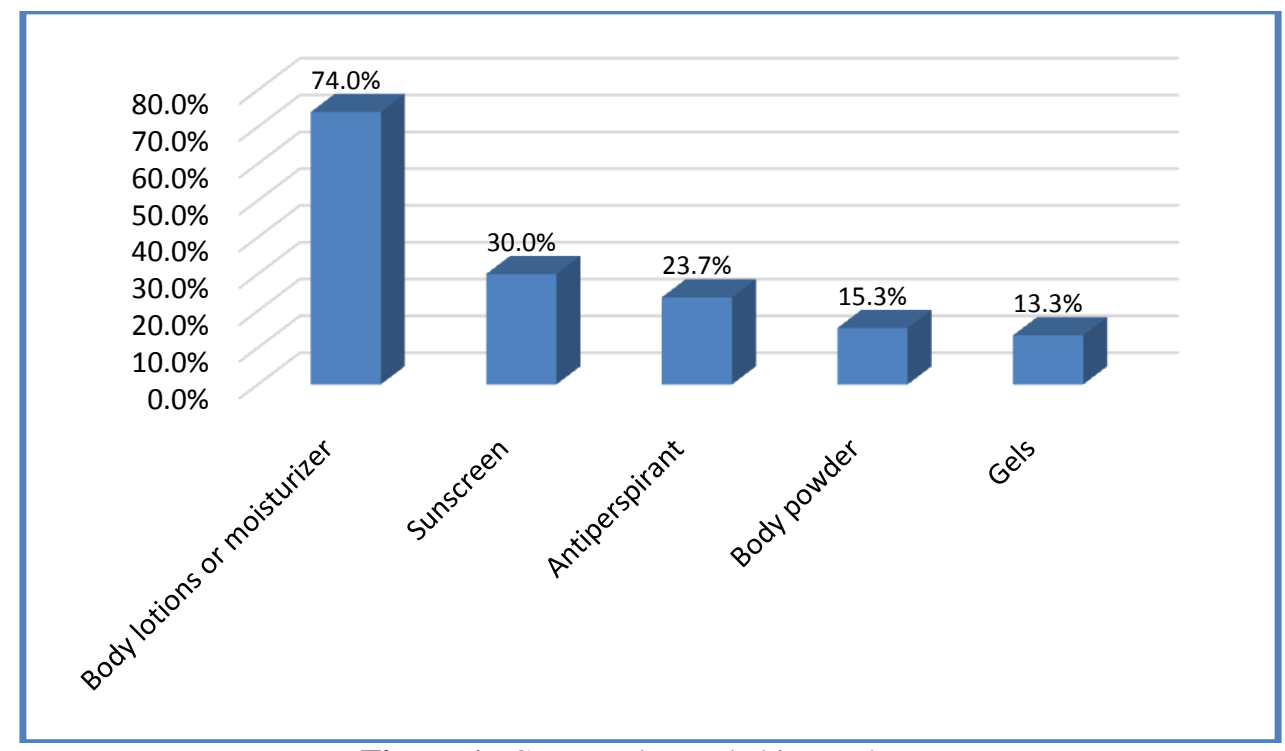

Figure 1:-Commonly used skin products.

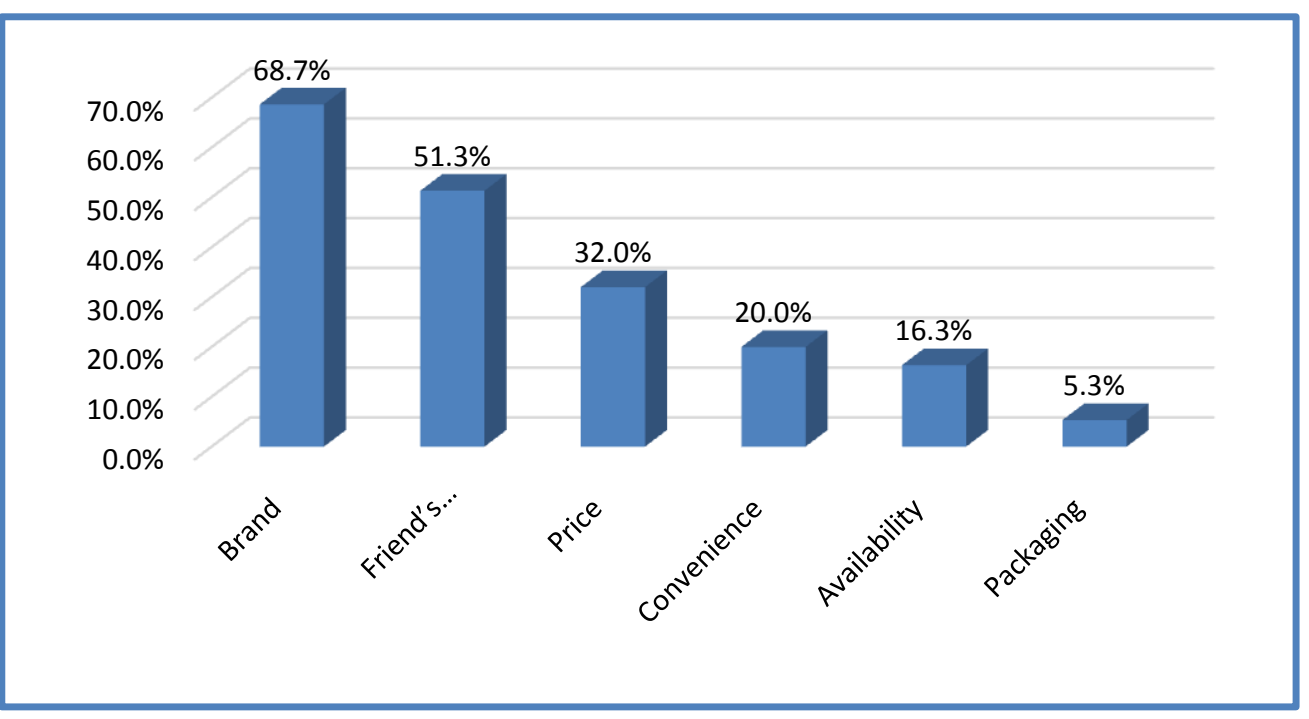

Figure 2:-Buying Behaviors of students. 


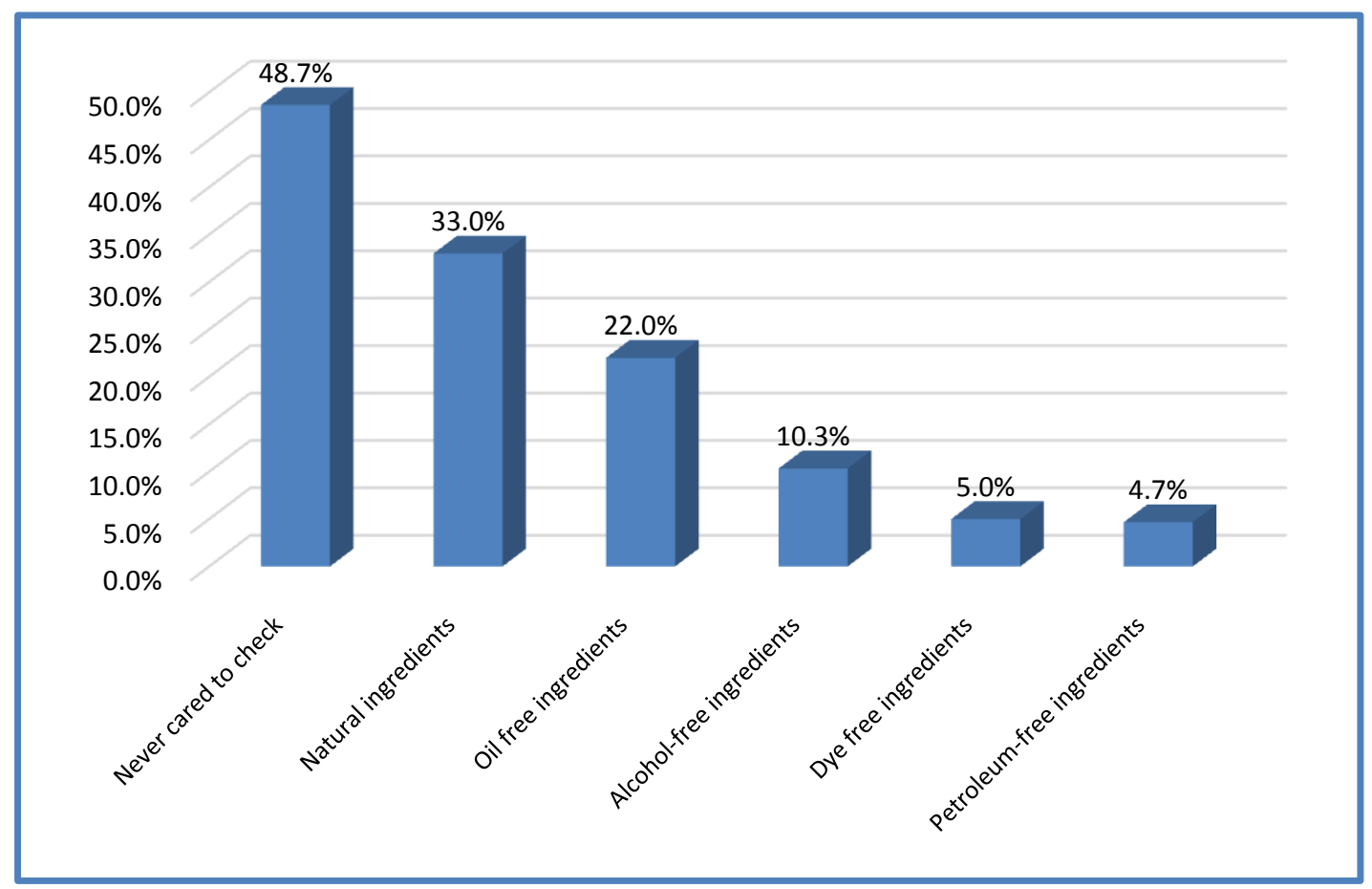

Figure 3:- Products-ingredients Buying factors.

\section{Discussion:-}

To our knowledge and after an extensive literature review, this is the first population-based study in Saudi Arabia to evaluate skin care routine and to study skin products buying factors.

Our study results indicated that only $(23.3 \%)$ of our students use regular facials as a routine, this rate is very low when compared with similar cross sectional study of a sample size (200), revealed that $100 \%$ of their respondents were skin care product users, the majority of respondents were from china. ${ }^{(9)}$

Most of ourmedical students use make up more often than skin care products, in contrast to another study comparing use of skincare products and make-up products, the use of skincare products was higher in East Asian cities Hong Kong, Taipei, Seoul and the three Chinese cities (Beijing, Shanghai, Guangzhou). Conversely, use of skincare products was higher in Southeast Asia and the two Indian cities (Delhi and Mumbai). It appears that the focus was on skincare in East Asia, including the three Chinese cities, and on make-up in Southeast Asia and India. ${ }^{(4)}$

Most commonly used skin product by our students were body lotions and moisturizers (74\%), our study results were consistent with results of previous studies, in which one of them revealed that face lotions were used by at least $(50 \%)$ of study responders. ${ }^{(4)}$ In another study, Results showed that when asked about what kind of facial cream the respondents used, the majority of all women said they use moisturising facial cream $(69,6 \%){ }^{(10)}$

We found that most of our students don't use sunblock before sun exposure (66\%)and some of them have a previous history of sunburn (29\%), in comparison to a study was done in al-Qassim, conducted in 2010 of sample size (1376), results showed that $(29.4 \%)$ had a history of suffering from sunburn before, $(8.3 \%)$ were using a sunscreen as a routine before sun-exposure, only (114) persons ( $8.3 \%$ ofstudy participants) reported use of sunscreen preparation. (11)

Results of our study revealed that a large number our students don't care to check the ingredient of their skin care/make up product before buying it $(48.7 \%)$, and only $(33 \%)$ cared about buying natural-ingredients products , in contrast, a study carried out for Finnish women, the respondents were also asked whether they would be willing to pay more for such facial skin care products that consist completely of organic ingredients (product consists of natural ingredients which have also been farmed so that no artificial fertilizers or pesticides have been used), Very 
few $(15,2 \%)$ respondents said they are willing to pay and nearly a half $(44,9 \%)$ reported they would not be ready to pay more for organic facial skin care products. ${ }^{(10)}$

Brand of the product was obviously the most important factor mattered to our students (78.7\%), our results goes along with the results of a study in terms that consumers take relatively less time to shop for brands they are familiar compared to brands that are new to them. ${ }^{(8)}$ A study which was done in 14 cities, Showed that in all three Chinese cities, reasonable price and brand image rank near the top for both make-up and skincare, a reasonable pricewas a common consideration among their women while among our students, women looked for different things other than price, they obviously had a little concern about the product price $(32.0 \%){ }^{(4)}$

Approximately $(51.3 \%)$ of our students take into consideration their friend's recommendation as an important evaluative factor when buying products and only $(5.3 \%)$ had concerns about product packaging, while in comparison to the results obtained from a study conducted also in this field revealed that among young women, the packaging $(8,9 \%)$, and consistency of a products were not considered very important. On the other hand, only $(8.9 \%)$ thought friends recommendations as determined factors when choosing one facial skin care product over another. ${ }^{(10)}$

\section{Conclusion and Recommendations:-}

Our society need to be more educated about the importance of getting a proper skin care routine, further studies with wider distribution of the questioner in different cities and to different age groups is advisable.

\section{Journal References:-}

1. AlGhamdi KM, AlHomoudi FA, Khurram H. Skin care: historical and contemporary views. Saudi Pharmaceutical Journal. 2014 Jul 31;22(3):171-8.

2. Al Robaee AA. Awareness to sun exposure and use of sunscreen by the general population. Bosn J Basic Med Sci. 2010 Nov 1;10(4):314-8.

3. Bangert C, Brunner PM, Stingl G. Immune functions of the skin. Clinics in dermatology. 2011 Aug 31;29(4):360-76.

4. Ganceviciene, Ruta, et al. "Skin anti-aging strategies." Dermato-endocrinology 4.3 (2012): 308-319.

5. Goh JY, Tan EF, Tiyu SX, Lee KC. The relationship between brand perceptions and brand satisfaction on skin care products (Doctoral dissertation, UTAR).

6. Kokoi, Isa. "Female buying behaviour related to facial skin care products." (2011).

7. Son DY, Lee EH. A Study on the Consumer's Attitude and Utilization Intention toward Full Ingredient Lists for Cosmetics: For Female Consumers. Family and Environment Research. 2013 Oct 30;51(5):513-26.

8. Xue TS, Mun HW, Chen OB, Fang TE, Chen LK, Yi GJ. Relationship between Brand Perceptions and Satisfaction: Empirical Study on Skin Products in Malaysia. Information Management and Business Review. 2015 Aug 1;7(4):23.

9. Xu S, Kwa M, Agarwal A, Rademaker A, Kundu RV. Sunscreen product performance and other determinants of consumer preferences. JAMA dermatology. 2016 Aug 1;152(8):920-7.

\section{Websites:-}

http://www.hakuhodo.jp/pdf/2013/20130117.pdf

https://www.aad.org/media/news-releases/study-most-americans-don-t-use-sunscreen 